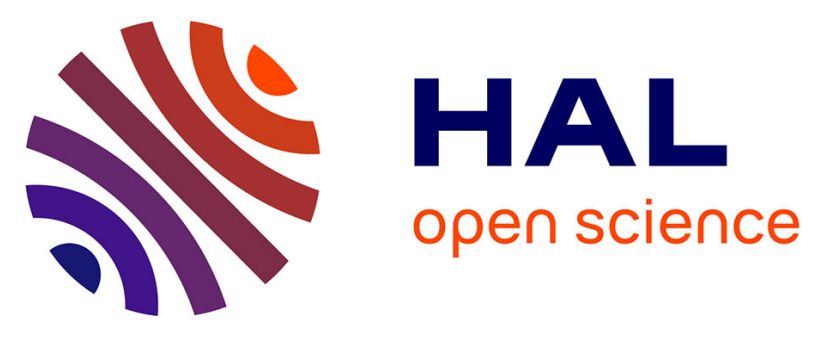

\title{
Structure Analysis of Hedgerows with Respect to Perennial Landscape Lines in Two Contrasting French Agricultural Landscapes
}

Sébastien da Silva, Florence Le Ber, Claire Lavigne

\section{To cite this version:}

Sébastien da Silva, Florence Le Ber, Claire Lavigne. Structure Analysis of Hedgerows with Respect to Perennial Landscape Lines in Two Contrasting French Agricultural Landscapes. International Journal of Agricultural and Environmental Information Systems, 2014, 5 (1), pp.19. 10.4018/ijaeis.2014010102 . hal-01057108

\section{HAL Id: hal-01057108 https://hal.science/hal-01057108}

Submitted on 27 Dec 2017

HAL is a multi-disciplinary open access archive for the deposit and dissemination of scientific research documents, whether they are published or not. The documents may come from teaching and research institutions in France or abroad, or from public or private research centers.
L'archive ouverte pluridisciplinaire HAL, est destinée au dépôt et à la diffusion de documents scientifiques de niveau recherche, publiés ou non, émanant des établissements d'enseignement et de recherche français ou étrangers, des laboratoires publics ou privés. 


\title{
Structure analysis of hedgerows with respect to perennial landscape lines in two contrasting French agricultural landscapes
}

\author{
Sébastien da Silva (1,3), Florence Le Ber (2), Claire Lavigne (3)
}

(1) LORIA, INRIA NGE, F-54506 Vandœuvre-lès-Nancy, France

(2) ICUBE, Université de Strasbourg/ENGEES, CNRS, F-67000 Strasbourg, France

(3) INRA, UR 1115, Plantes et Systèmes de culture Horticoles, F-84000 Avignon, France

Abstract. Characterizing the spatial distribution of hedgerows over landscapes is important for understanding the effects of this distribution on the dynamics of plant and animal populations. Because hedgerows are planted or managed, we hypothesized that their distribution depends on the presence of other linear landscape elements, namely, roads and channels. Using proximity analyses, we thus assessed how the spatial distribution of hedgerows was impacted by the position of these linear landscape elements and the spatial extent of this impact for two contrasting agricultural landscapes. The results indicate that hedgerows were generally associated at short distances with other elements (100-150 m). Hedgerows had different association patterns depending on their orientation in one of the two landscapes. In that same landscape, within-landscape heterogeneity was related to different association patterns. These results indicate that models of the spatial distribution of hedgerows would gain from being based on the location of roads and channels in the studied landscape.

Keywords: Agricultural landscapes, Brittany, Hedgerows, Provence, Proximity analysis, Segments, Spatial structure. 


\section{Introduction}

The structure of landscapes impacts the dynamics of plant and animal populations that live on these landscapes. This structure can be characterized by the landscape composition, i.e., the relative areas or numbers of elements that compose these landscapes, and the landscape configuration, i.e., the spatial distribution of these elements. Understanding how landscape structure impacts population dynamics is a key question for species conservation issues (e.g., Bennett et al., 2006) but is also important in agro-ecological studies (e.g., Geiger et al., 2009). In empirical studies, much attention has been devoted to understand how the spatial distribution of patchy habitats may affect the abundance and dispersal of particular species (e.g., Chaplin-Kremer et al., 2011; Mazzi \& Dorn, 2012 for agricultural pests and pest enemies). Accordingly, numerous indices have been developed to characterize these elements and their spatial distribution. These indices may relate to the elements themselves (area, shape), to the connectivity among elements of a single type or to landscape heterogeneity at different scales (Riitters et al., 1995). These indices have also been used in modeling approaches that aimed to unravel how the interactions between landscape structure and population dynamics affect the observed patterns of species abundances and genetic structures (Wiegand et al., 1999).

The characterization of the spatial distribution of linear elements (i.e., elements that can be represented with lines, e.g., irrigation channels and hedgerows) over landscapes has received relatively little attention. However, hedgerows are a prominent linear landscape feature and play multiple roles for species inhabiting the landscape. They may furnish habitat for undercover or tree species, corridors facilitating movement of individuals between forest patches or, in contrast, an obstacle to dispersal for species specializing in open areas (Burel, 1996; Davies \& Pullin, 2007). Furthermore, their windbreak and shade effects may produce local modifications of the microclimate and wind turbulence, and these effects may impact species survival or reproduction (e.g., Tyson et al., 2007).

The present study is methodological and does not consider ecological processes that are affected by hedgerows. Moreover, we focus on the characterization of the spatial distribution of hedgerows, in contrast to previous research that designed methods to characterize the type 
and composition of hedgerows (Paletto and Chincarini, 2012; Larcher and Baudry, 2013). Several landscape-level indices have already been proposed by Groot et al. (2010) and applied to hedgerows in an agro-ecological zone in the Netherlands. A recent study further characterized the density of green lines (hedgerows and grassy strips) over European landscapes (van der Zanden et al., 2013). However, local spatial interactions between landscape elements were not considered in these studies.

The locations of hedgerows over the landscapes are not random. At the European scale, van der Zanden et al. (2013) showed that spatial autocorrelation-based methods performed poorly because the locations of "green lines" depended on the occurrence of other land uses such as cash crops or the stocking densities of herbivores as well as on wind speed. In our study regions, hedgerows have been historically used as fences between neighboring fields and have been planted along roads, tracks and water courses for wood production for households (Meynier, 1958; Liagre, 2006). In windy regions, hedgerows are further grown for their windprotecting effects (Guyot, 1997). In certain instances, hedgerows are also planted along field edges to promote pest enemies (Ouin et al., 2008). As a consequence, it can be expected that the spatial distribution of hedgerows over landscapes presents specific characteristics based on (i) the function of these hedgerows (e.g., fences or windbreaks) and (ii) the spatial distribution of other more perennial elements such as roads and water channels (or ditches). We address these two expectations in the present study, and we further characterize the spatial extent over which expectation (ii) is realized.

In addition to the need to consider other landscape elements, the methodology that we designed was guided by our intention to build neutral models (Turner, 1991) of hedgerow landscapes. Neutral landscape models can indeed be used to study the effect of variation in landscape patterns on ecological processes (Meyer et al., 2012). We planned to rely on recent geometrical approaches such as those proposed by Gaucherel et al. (2006) and Le Ber et al. (2009) to simulate patchy (agricultural) landscapes. In these approaches, real landscapes are characterized by a distribution of plot centroids that is used as a basis for building polygonal tessellations. Previously, linear elements have not been considered in those approaches. Given this aim, from a methodological perspective, we chose an approach that relates to proximity analyses that are frequently used in spatial statistics for landscape ecology to analyze 
relationships between species abundances and nearby landscape features (e.g., Ricci et al., 2009; Martin \& Fahrig, 2012). This approach allows an assessment of the ways in which the characteristics of local hedgerows (length and orientation) affect their association with their short- to medium-distance neighbors. An assessment of this type would not be possible with spatial network analyses, which are generally used to study the spatial distributions of hedgerows (De Smith et al., 2007).

The results are presented for two contrasting French agricultural landscapes. The first landscape is in southeastern France. It is primarily an area of pome fruit orchards, and it has a dense cover of windbreaks and irrigation channels. The second landscape is in Brittany, in western France. It is characterized by a "bocage"-type hedgerow pattern, and the water network consists primarily of ditches.

\section{Theoretical background}

Overall, our approach is related to the large family of proximity analyses. It is based on two methods. First, it relates to marked point processes, and in particular Ripley's K function approach, in that it compares observed to expected numbers of neighbors within a set of increasing distances (Ripley, 1981). Second, it relates to regression analyses that explain the presence/ abundance of an element (e.g., a species) as a function of its surrounding environment and compares the influence of different environmental variables (e.g., Ricci et al., 2009). However, our proposed approach differs because (i) we considered elements that are segments rather than points, a choice that has consequences in terms of distances between elements and thus of the definition of neighborhoods; (ii) we aimed to compare the environment of different types of hedgerows, not specifically factors that explained their presence.

All linear landscape elements were split into straight segments that were characterized by their length and orientation. The proximity analysis that we propose is based on the analysis of the number of elements (that are also segments) in the neighborhood of a given segment. This number is compared with an average number computed on a very large neighborhood. The ratio of the observed to the average number of elements in the neighborhood of a given 
segment $S$ (termed "relative number of elements") indicates whether these elements are overor underrepresented in the neighborhood of $S$. Comparisons between these "relative numbers of elements" can also be performed for different element types and orientations.

\section{Characterizing the neighborhood of one segment}

Distance between segments. There are several methods to compute the distance between two spatial objects. Usually, the objects are assimilated to their centroids and a point distance is calculated, but this distance gives a poor notion of neighborhood, e.g., two segments can be connected, whereas their centroids are far from each other. To represent neighborhood, we thus used a pseudo-distance defined as follows. The distance between two segments is computed as the smallest distance between all points of the two segments, i.e., for two segments $S$ and $S^{\prime}$,

$$
\operatorname{Dist}\left(S, S^{\prime}\right)=\min _{x \text { in } S, x^{\prime} \text { in } S^{\prime}} d\left(x, x^{\prime}\right), \text { where } d \text { is the Euclidean distance. }
$$

Number of neighbors of a segment. The number of elements that are neighbors of the $S$ segment and closer than a distance $b$ from that segment is

$$
N_{o}(S, b)=\left|\left\{S^{\prime} \mid \operatorname{Dist}\left(S, S^{\prime}\right)<b\right\}\right|
$$

Neighborhood of a segment. The neighboring area of a segment of length $L$ at distance $b$ is calculated as

$$
B(L, b)=\Pi * b^{2}+2 * L * b .
$$

Expected number of elements in the neighborhood of a segment. Let $A$ be the surface area of a large area and $N_{A}$ the number of elements in this area. $N_{A} / A$ is the average density of elements in this area. For a segment of $A$ whose length is $L$, the local expected number of neighboring elements closer than distance $b$ is

$$
N_{e}(L, b)=B(L, b) * N_{A} / A \text {. }
$$

Relative number of elements in the neighborhood of a segment. The relative number of neighboring elements for a $S$ segment and a buffer of width $b$ is, thus, calculated as the ratio 


$$
N_{r}(S, b)=N_{o}(S, b) / N_{e}(L, b)
$$

where $L$ is the length of segment $S$ and $N_{o}(S, b)$ is the observed number of elements in the neighborhood as defined above.

Neighboring elements oriented in a certain direction $\Theta=[\theta 1 ; \theta 2]$ relative to the $S$ segment can be considered separately. In this case,

$$
\begin{gathered}
N_{o}^{\Theta}(S, b)=\mid\left\{S^{\prime} \mid \operatorname{Dist}\left(S, S^{\prime}\right)<b \text { and angle }\left(S, S^{\prime}\right) \epsilon \Theta\right\} \mid . \\
N_{r}^{\Theta}(S, b)=N_{o}^{\Theta}(S, b) / N_{e}(L, b),
\end{gathered}
$$

where $\Theta=[0 ; 2 \Pi], N_{r}^{\Theta}(S, b)=N_{r}(S, b)$.

The means and standard errors of $N_{r}^{\Theta}(S, b)$ can be calculated over a set of segments.

\section{Testing over- or underrepresentation of elements in neighborhoods}

The $N_{r}(S, b)$ value tends toward 1 when $B(L, b)$ tends toward $A$, whereas $N_{r}^{\Theta}(S, b)$ tends toward $p^{\Theta}$, the proportion of elements of a given type that are oriented in the $\Theta$ direction relative to segment $S$ in area $A$.

Values of $N_{r}(S, b)>1$ (respectively, $\left.N_{r}^{\Theta}(S, b)>p^{\Theta}\right)$ indicate that elements are overrepresented in the $b$-wide neighborhoods of segments. If $b$ is a small distance, this overrepresentation can be interpreted as an attraction between the $S$ segments and sampled elements. In contrast, values of $N_{r}(S, b)<1$ (respectively, $\left.N_{r}^{\Theta}(S, b)<p^{\Theta}\right)$ indicate that elements are underrepresented in these neighborhoods. A statistical test of over- or underrepresentation can be performed by deriving the distributions of $N_{r}(S, b)$ (respectively, $\left.N_{r}^{\Theta}(S, b)\right)$ under the hypothesis of random distribution of segments over the study area and comparing the observed values to the simulated quantiles. Such a distribution can be obtained by randomly locating the segments (keeping their length and orientation) over the study area and calculating the corresponding $N_{r}(S, b)$ values a large number of times. 


\section{Comparing the relative numbers of different elements in neighborhoods of a given size}

The general approach described above can be applied to various types of elements (e.g., hedgerows, channels, road segments) and on different scales. Accordingly, one may wish to compare relative numbers of different element types. Variations in relative numbers of elements in neighborhoods can be analyzed with linear models that include the element types as explanatory variables. Because segments may be statistically dependent due to shared neighborhoods, the significance of explanatory variables cannot be assessed using classical Fisher distributions for the F statistics. An empirical null distribution for the F statistic can be derived using permutation tests. Such a null distribution corresponds to the hypothesis that, given the observed locations of elements, elements of the different types occur in similar relative numbers for a given neighborhood size. Simulated data sets under the null hypothesis are thus obtained by permutation of the labels of the element types.

The complete structures of the statistical model and of the permutation scheme depend on that of the data set, in particular, if different geographical areas or segment types are analyzed simultaneously (see below).

\section{Materials and methods}

\section{Data sets}

The analysis was based on two French datasets. The first set ("the low Durance valley") described an approximately $70 \mathrm{~km}^{2}$ agricultural landscape in southeastern France (coordinates in WGS84 system from $43^{\circ} 46^{\prime} 27^{\prime \prime} \mathrm{N}$ to $43^{\circ} 51^{\prime} 23^{\prime \prime} \mathrm{N}$ and from $4^{\circ} 51^{\prime} 12^{\prime \prime} \mathrm{E}$ to $\left.4^{\circ} 57^{\prime} 34^{\prime \prime} \mathrm{E}\right)$. The principal agricultural production consists of orchards, primarily pome fruit (apples and pears), and some vegetables. The region is characterized by a high density of windbreak hedgerows. Data on the road and hydrological networks were provided by the French National Institute for Geography (BD TOPO ${ }^{\circledR}$, IGN). All 11,501 hedgerows were manually digitized with ArcView (Version 9.1, ESRI) from an aerial photograph (BD ORTHO®, IGN, 2004 - pixel size: $0.5 \mathrm{~m}$ ) in the form of polylines. 
The second set describes an approximately $120 \mathrm{~km}^{2}$ agricultural landscape of Brittany (coordinates in WGS84 system from $48^{\circ} 25^{\prime} 32^{\prime \prime} \mathrm{N}$ to $48^{\circ} 34^{\prime} 06^{\prime \prime} \mathrm{N}$ and from $1^{\circ} 31^{\prime} 39^{\prime \prime} \mathrm{W}$ to $\left.1^{\circ} 39^{\prime} 07^{\prime \prime} \mathrm{W}\right)$. The northern part of the area consists of large fields, whereas the southern part is a typical bocage landscape of Brittany with a high density of hedgerows (Lotfi et al., 2010). The 7561 hedgerows were mapped by exhaustive field monitoring of a digitized map of administrative parcel limits (Courtesy, Costel Rennes, France). Data on the road and hydrological networks were provided by the French National Institute for Geography (BD TOPO®, IGN).

\section{Data manipulation}

To make the data comparable in the two data sets, all hedgerows, roads and channels were individualized by splitting polylines into unidirectional segments. For example, two contiguous but perpendicular hedgerows were considered as two different segments. Accordingly, we based our study on three segment types that refer to the type of element (road, hedgerow or channel) from which they were built. Because the digitization of hedgerows had been performed differently in the two landscapes, this procedure had a large impact on the number of hedgerow segments in the Brittany but not in the Durance landscape. The 11,501, 183 and 796 polylines for hedgerows, channels and roads, respectively, in the Durance landscape were transformed into 11,556, 2014 and 3737 segments, respectively. In the Brittany landscape, the corresponding 7561, 328 and 2516 polylines were transformed into 14,819, 9152 and 43,416 segments, respectively. Each segment was then characterized by its length and orientation.

\section{Selecting windows with various segment densities}

To characterize the heterogeneity of the two studied landscapes in terms of linear elements, we split landscapes into windows of increasing size (from $200 \mathrm{~m}$ x $200 \mathrm{~m}$ to $1300 \mathrm{~m}$ x $1300 \mathrm{~m}$ ). We then plotted the distribution of the number of hedgerow, road and channel segments per window as a function of window size. From this distribution, we chose a window size $(1100 \mathrm{~m} \times 1100 \mathrm{~m})$ having a sufficient mean and variance of the number of segments (not shown). 
Windows that were located on the edge of the landscape and windows with a non-complete neighbor were removed from further analyses to avoid edge effects, which are important in spatial analyses. The low Durance valley landscape was, thus, split into 64 windows and the Brittany landscape into 35 windows. Furthermore, each window was associated with a target area consisting of this window and its eight neighboring windows, within which segment neighbors will be considered. One typical window for each landscape is presented in Figure 1.

Figure 1: Two typical windows and their target areas in low Durance valley (left) and Brittany (right). Central squares represent the $1100 \mathrm{~m}$ x $1100 \mathrm{~m}$ windows. Green color: hedgerows, blue: channels, black: roads.
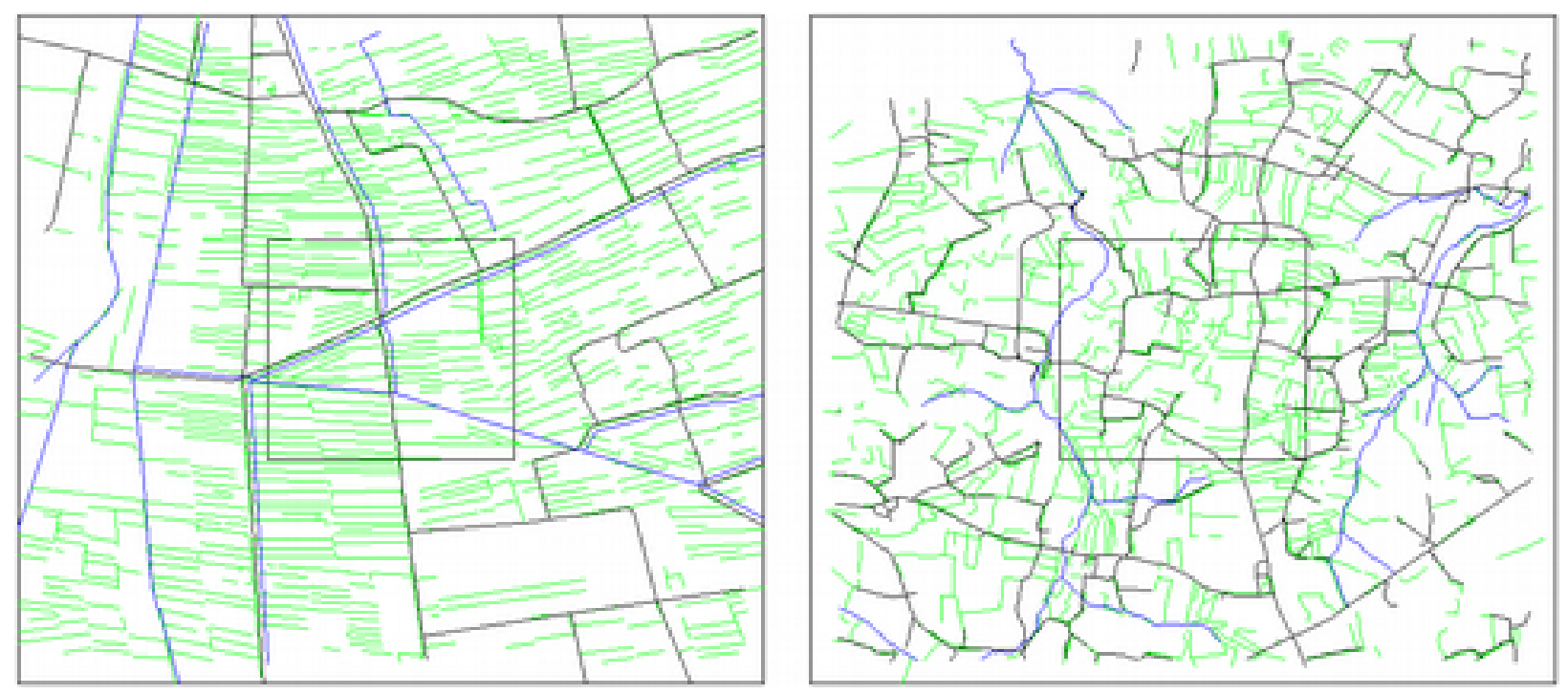

We then grouped windows into classes to later examine the impact of window characteristics on the characteristics of hedgerow neighborhoods. For this purpose, each window was characterized by four variables of interest: its number of hedgerow and road segments and the number of hedgerow and road segments of its target area. Classification of windows according to these characteristics was performed using a hierarchical clustering approach (function hclust in package Stats from R Commander V1.8-1). This classification resulted in five window classes in the low Durance valley landscape and six in Brittany (see results).

We chose 29 windows in the Durance landscape and 17 windows in the Brittany landscape, corresponding to approximately one-half of the windows in each of these classes. This choice 
was guided by the aim of avoiding neighboring windows (i.e., one edge in common) for further analyses.

\section{Analysis of hedgerow distributions with respect to perennial elements in chosen windows}

To assess the possible influence of perennial linear landscape elements on hedgerows, we assessed, in each focus window and for each hedgerow segment:

1. Whether its closest neighbor was a hedgerow, a road or a channel segment.

2. Whether its parallel or perpendicular closest neighbor was a hedgerow, a road or a channel segment.

3. The relative number of hedgerow, road or channel segments in areas surrounding each hedgerow segment. These areas were of increasing size, determined by a maximal distance to each hedgerow segment. We considered either all neighbors or only those parallel or perpendicular to the target hedgerow segment.

4. The same procedure was followed as in (3) except that we separately considered the eastwest oriented hedgerows and those that were perpendicular to them.

5. To compare the relative numbers of neighbors $N_{r}^{\Theta}(S, b)$ between element types and relative orientations at the landscape scale or between classes, they were all standardized. The standardized values were computed by dividing $N_{r}{ }^{\Theta}(S, b)$ by the mean of $N_{o}^{\Theta}(S, b)$ for $b=500 \mathrm{~m}$ over all $S$ hedgerow segments in the focus window.

Number and relative number of elements in a segment neighborhood. Given a segment $S$ and a distance $b$, the numbers of neighboring hedgerows $\left(H_{o}(S, b)\right)$, roads $\left(R_{o}(S, b)\right)$ or channels $\left(C_{o}(S, b)\right)$ were computed as defined in section 2. Target areas were used as a reference for computing the relative numbers of hedgerow $\left(H_{r}(S, b)\right)$, road $\left(R_{r}(S, b)\right)$ and channel $\left(C_{r}(S, b)\right)$ segments. These ratios were computed and averaged over all segments of each selected window for $b$ in $\{20,40, \ldots 180,200,300,400,500\}$.

Relative orientation of a segment and its neighbors. Furthermore, for a given segment, neighbors were classified according to their angle with the segment direction: neighbors parallel to this segment were those forming an angle in the interval $[-\Pi / 9 ;+\Pi / 9]$ with the 
segment direction, and neighbors perpendicular to this segment were those forming an angle in the interval $[7 \Pi / 18 ; 11 \Pi / 18]$ with it. In this case, the average relative number of segments of hedgerows $\left(H_{r}^{\Theta}(S, b)\right)$, roads $\left(R_{r}^{\Theta}(S, b)\right)$ or channels $\left(C_{r}^{\Theta}(S, b)\right)$ in a buffer of width $b$ converges to the proportion of segments of that specific element type that are parallel (respectively, perpendicular) to hedgerow segments in the considered window when $b$ increases.

Classification of hedgerows following their orientation. Lastly, based on the distribution of hedgerow segment orientations, hedgerows were separated into two types according to their orientation in the low Durance valley: HNS hedgerows had an angle of $[-\Pi / 9 ;+\Pi / 9]$, and HWE (windbreak) hedgerows had an angle of $[\Pi / 3$; 5П/9] with respect to the North-South line. In Brittany, the angles with respect to the North-South line were $[-\Pi / 9 ;+\Pi / 9]$ for HNS and $[4 \Pi / 9 ; 2 \Pi / 3]$ for HWE hedgerows.

Tests of under- or overrepresentation in neighborhoods. Tests of the under- or overrepresentation of hedgerow, road and channel segments in the neighborhoods of hedgerow segments were performed by deriving the distributions of $H_{r}(S, b), R_{r}(S, b)$ and $C_{r}(S, b)$ for 100 random distributions of hedgerows within the target areas. The hedgerows were redistributed within their window of origin.

\section{Statistical analysis of the impact of hedgerow type and neighbor type and orientation on the relative number of neighbors.}

Variations in the relative numbers of neighboring elements at each distance were analyzed separately for each landscape using mixed linear models. The explanatory variables were win dow class (qualitative, either five or six levels), hedgerow type (qualitative, three levels), neighbor type (qualitative, three levels), neighbor relative orientation (two levels) and all twoway interactions. The empirical null distribution for the $\mathrm{F}$ statistic was obtained by running the same mixed models on 1000 permuted data sets. Permutations of the relative numbers of neighbors were performed between segment types within windows to reflect the structure of the data set. 


\section{Results}

We first present a global description of the linear elements in the two study landscapes and show the diversity of situations within and between landscapes. We then illustrate the global structure of hedgerows and their relationship to roads and channels using the two windows presented on Figure 1. We lastly present the overall results.

\section{Chosen windows and diversity within and among landscapes}

The classification procedure defined five classes in the low Durance valley and six in Brittany. These classes comprised different average numbers of hedgerow segments (from 58 to 165 per window in the Durance landscape and from 167 to 406 per window in the Brittany landscape) and of road segments (from 8 to 57 per window in the Durance landscape and from 417 to 601 per window in the Brittany landscape) but differed little in terms of numbers of channel segments per window. The ratio of HWE to HNS hedgerow segments varied from 1.6 to 5 per window in the Durance valley and was more stable, varying from 0.9 to 1.3 , in the Brittany landscape (Table 1).

Table 1: Numbers of segments (mean \pm sd) of each type (hedgerows, roads and channels) in windows and target areas and of HNS and HWE hedgerow segments in windows for the different window classes in the two studied landscapes (low Durance valley and Brittany).

\begin{tabular}{|c|c|c|c|c|c|c|c|c|}
\hline & & \multicolumn{4}{|c|}{ Hedgerows } & \multicolumn{2}{|c|}{ Roads } & \multirow{3}{*}{$\begin{array}{c}\text { Channels } \\
\text { All } \\
\text { Window }\end{array}$} \\
\hline & & \multicolumn{2}{|c|}{ All } & \multirow{2}{*}{$\begin{array}{c}\text { HNS } \\
\text { Window }\end{array}$} & \multirow{2}{*}{$\begin{array}{c}\text { HWE } \\
\text { Window }\end{array}$} & \multicolumn{2}{|c|}{ All } & \\
\hline & & Window & Area & & & Window & Area & \\
\hline \multicolumn{9}{|l|}{ Durance } \\
\hline \multirow{5}{*}{ Class } & 1 & $165 \pm 33$ & $1191 \pm 71$ & $25 \pm 17$ & $84 \pm 20$ & $42 \pm 18$ & $330 \pm 57$ & $21 \pm 15$ \\
\hline & 2 & $237 \pm 79$ & $1528 \pm 115$ & $66 \pm 36$ & $106 \pm 16$ & $57 \pm 20$ & $405 \pm 36$ & $24 \pm 6$ \\
\hline & 3 & $58 \pm 29$ & $543 \pm 88$ & $10 \pm 8$ & $29 \pm 19$ & $8 \pm 7$ & $108 \pm 35$ & $24 \pm 10$ \\
\hline & 4 & $95 \pm 26$ & $808 \pm 56$ & $18 \pm 7$ & $55 \pm 22$ & $22 \pm 12$ & $172 \pm 50$ & $12 \pm 8$ \\
\hline & 5 & $142 \pm 32$ & $988 \pm 44$ & $18 \pm 14$ & $93 \pm 28$ & $31 \pm 14$ & $257 \pm 64$ & $17 \pm 11$ \\
\hline \multicolumn{9}{|l|}{ Brittany } \\
\hline \multirow{6}{*}{ Class } & 1 & $406 \pm 64$ & $2495 \pm 151$ & $130 \pm 55$ & $121 \pm 33$ & $601 \pm 54$ & $4116 \pm 98$ & $109 \pm 51$ \\
\hline & 2 & $309 \pm 50$ & $2285 \pm 146$ & $90 \pm 30$ & $86 \pm 10$ & $469 \pm 138$ & $3517 \pm 178$ & $87 \pm 65$ \\
\hline & 3 & $177 \pm 30$ & $1516 \pm 129$ & $46 \pm 27$ & $60 \pm 16$ & $444 \pm 43$ & $3666 \pm 90$ & $92 \pm 61$ \\
\hline & 4 & $167 \pm 37$ & $1287 \pm 113$ & $47 \pm 14$ & $46 \pm 17$ & $555 \pm 151$ & $3951 \pm 119$ & $38 \pm 53$ \\
\hline & 5 & $174 \pm 67$ & $1233 \pm 76$ & $57 \pm 24$ & $62 \pm 24$ & $417 \pm 45$ & $3225 \pm 41$ & $77 \pm 107$ \\
\hline & 6 & $241 \pm 79$ & $1669 \pm 132$ & $91 \pm 39$ & $82 \pm 37$ & $427 \pm 73$ & $3359 \pm 97$ & $106 \pm 66$ \\
\hline
\end{tabular}


Classes were generally located in different areas of the landscape. In the low Durance valley, windows of classes 1 and 2 were located primarily in the north and northeast of the area, with large numbers of hedgerow and road segments. In contrast, the southwestern part of the area was primarily composed of windows of classes 3 and 4, with smaller numbers of hedgerow and road segments. A line consisting of intermediate windows of class 3 extended between these two areas. In Brittany, windows of classes 1 and 2, with the largest average numbers of hedgerow segments, were located in the southwestern portion of the area. In contrast, windows of class 4 , with the lowest average number of hedgerows, were in the northeast. Intermediate classes 3, 5 and 6 were located primarily in the center of the area.

\section{Closest neighbors}

The closest neighbors of hedgerows were primarily hedgerows in the two landscapes representing, on average, (mean and sd over classes) $69 \pm 14 \%$ and $72 \pm 7 \%$ of the neighbors of HNS and HWE hedgerow segments, respectively, in the low Durance valley and $71 \pm 13 \%$ and $67 \pm 12 \%$ of the neighbors of HNS and HWE hedgerow segments, respectively, in Brittany, whereas channels were the least frequent neighbors. Roads were globally more frequent neighbors in Brittany than in the low Durance valley. This finding is consistent with the higher proportion of roads relative to hedgerows in Brittany. Furthermore, roads in Brittany were more frequently the closest neighbor when they were perpendicular to hedgerow segments than when they were parallel to them. The pattern was less clear in the Durance valley (Figure 3). 
Figure 2: Location of window classes in each landscape (left) and number of windows per class in the sample used for proximity analyses and over the landscape (right). Windows of the sample are marked with 'o'. Top: Durance valley, bottom: Brittany.

\section{Durance valley}

\begin{tabular}{|c|c|c|c|c|c|c|c|c|c|c|c|}
\hline & 0 & 1 & 2 & 3 & 4 & 5 & 6 & 7 & 8 & 9 & 10 \\
\hline 0 & & & & & & & & & & & \\
\hline 1 & & & 0 & & 14 & & 0 & & 0 & & \\
\hline 2 & & & & 0 & & 0 & & 0 & & 0 & \\
\hline 3 & & & 0 & & 9 & & 0 & & 0 & & \\
\hline 4 & & & & 9 & \#\# & 6 & & 0 & & 0 & \\
\hline 5 & & & 尚 & \# \# & 4 & & 1 & & 11 & & \\
\hline 6 & & & & 非 & \#\# & \#制 & 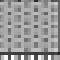 & 0 & & 0 & \\
\hline 7 & & & & 9 & 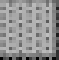 & 非 & 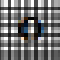 & & 1 & & \\
\hline 8 & & & & & 1 & \# & \#\# & 10 & & 0 & \\
\hline 9 & & & & & & & & & & & \\
\hline 10 & & & & & & & & & & & \\
\hline
\end{tabular}

\section{Brittany}

\begin{tabular}{|c|l|l|l|l|l|l|l|l|l|}
\hline & 0 & 1 & 2 & 3 & 4 & 5 & 6 & 7 & 8 \\
\hline 0 & & & & & & & & & \\
\hline 1 & & & & & & & & & \\
\hline
\end{tabular}

\section{Number of windows

\begin{tabular}{|c|c|c|}
\hline Colo & Sample & Landscape \\
\hline
\end{tabular}

\begin{tabular}{|c|c|c|c|}
\hline & 12 & 23 & 1 \\
\hline & 2 & 5 & 2 \\
\hline \#\#\# & 5 & 12 & 3 \\
\hline & 5 & 12 & 4 \\
\hline & 5 & 12 & 5 \\
\hline & 29 Wind. & 64 Wind. & \\
\hline
\end{tabular}

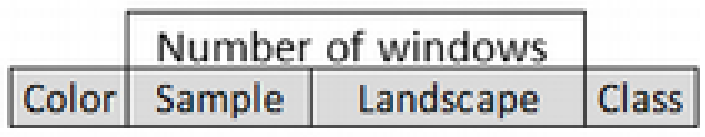

\begin{tabular}{|c|c|c|c|}
\hline & 2 & 4 & 1 \\
\hline & 2 & 4 & 2 \\
\hline 非册曲 & 3 & 6 & 3 \\
\hline & 5 & 10 & 4 \\
\hline & 2 & 4 & 5 \\
\hline 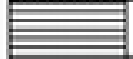 & 3 & 7 & 6 \\
\hline 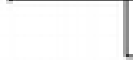 & 17 Wind. & 35 Wind. & \\
\hline
\end{tabular}


Figure 3: Proportion of each type of closest neighbor for each class of window. The results are presented for each landscape (left: low Durance valley, right: Brittany), for each type of hedgerow (1): HWE hedgerows, 2) HNS hedgerows) and for the parallel and perpendicular relative orientations. The neighbor types are roads (black), hedgerows (white) or channels (grey).

\section{1) HWE Hedgerows}

\section{Durance valley}
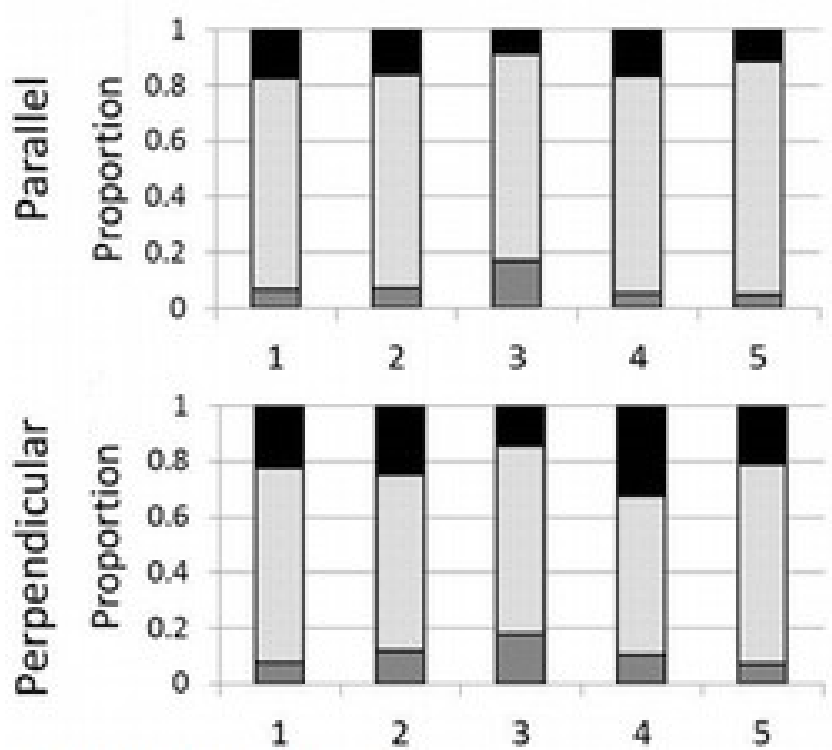

2)HNS Hedgerows
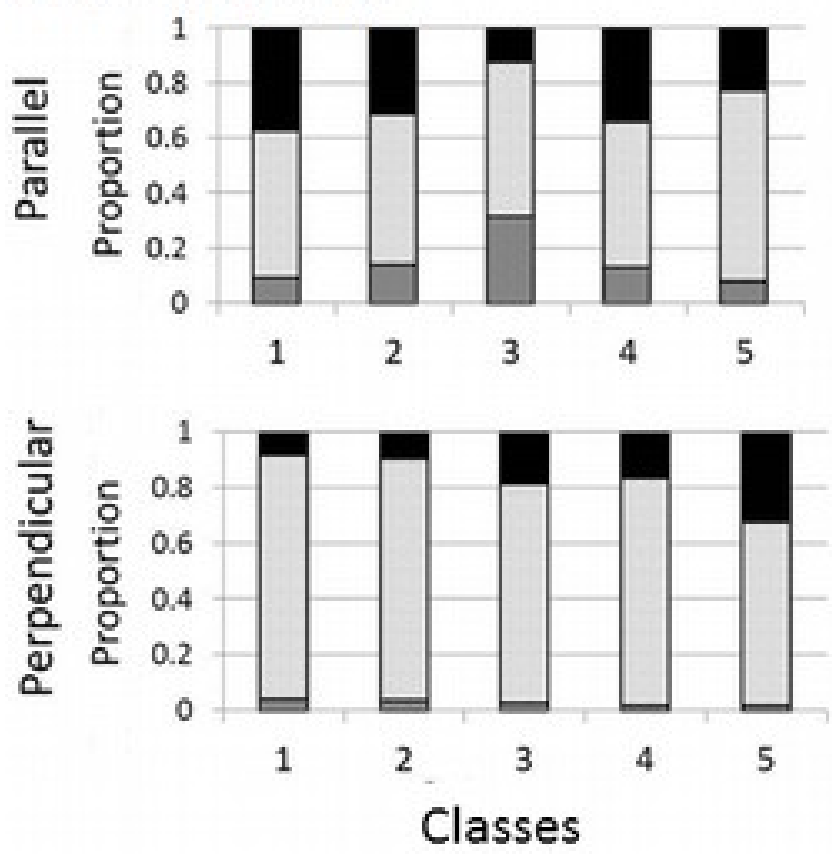

\section{Brittany}
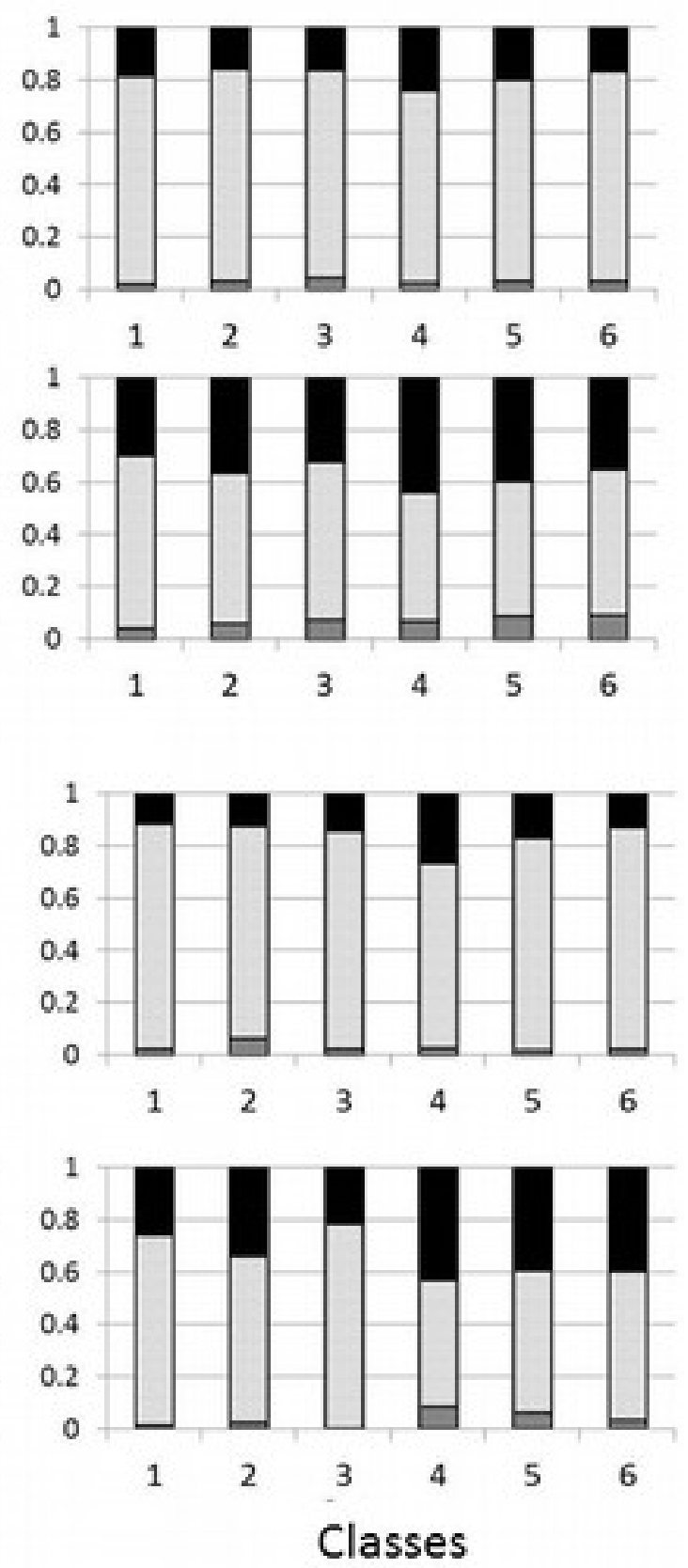


\section{Relative numbers of hedgerow, road and channel segments in neighborhoods of hedgerow segments}

\section{Neighbor distributions on two typical windows}

Based on the consideration of all hedgerow segments together in the two typical windows presented in Figure 1, the relative numbers $H_{r}(S, b), R_{r}(S, b), C_{r}(S, b)$ of each type of segment (hedgerows, roads and channels) decreased in the first $150 \mathrm{~m}$ toward the threshold corresponding to the proportion of segments of that type that were either parallel or perpendicular to hedgerows. Most segment types were thus overrepresented at short distances from hedgerows, indicating a short-distance association with them (and below $50 \mathrm{~m}$ for perpendicular hedgerows). The only exception concerned the relative number of hedgerows parallel to hedgerows in D5_6. This number was almost constant, with a peak located at approximately $100 \mathrm{~m}(\mathrm{P}>0.05$ below $150 \mathrm{~m}$ except around $100 \mathrm{~m})$, consistent with the apparently regular distribution of hedgerows in Figure 1. The overrepresentation at short distances primarily concerned hedgerows in window B9_2, showing a strong association between hedgerows and primarily concerned roads and channels in window D5_6 ( $\mathrm{P}<0.05$ for all distances below $150 \mathrm{~m}$ for roads and channels). The threshold values at long distances differed in window D5_6 between the parallel and the perpendicular directions, with hedgerows the most frequent elements in the parallel direction and the least frequent in the perpendicular direction of hedgerow segments. Such a pattern was not observed in B9_2.

The separate consideration of HWE and HNS hedgerow segments highlighted differences between these segment types, primarily in window D5_6. In window D5_6, both types of hedgerows were located next to roads, but HWE hedgerow segments were primarily perpendicular to these roads $(\mathrm{P}<0.05$ for distances below $150 \mathrm{~m}$ for the perpendicular but not the parallel orientation), whereas HNS hedgerow segments were parallel $(\mathrm{P}<0.05$ for distances below $150 \mathrm{~m}$ for the parallel orientation). Furthermore, HNS hedgerows were preferentially located next to perpendicular hedgerows $(\mathrm{P}<0.05$ for distances below $100 \mathrm{~m})$, whereas HWE hedgerow segments were not. Differences between HNS and HWE hedgerows were less apparent in B9_2. A particularity of B9_2 was that channels had a North-South 
orientation and were thus underrepresented as parallel neighbors of HWE hedgerows as well as perpendicular neighbors of HNS hedgerows.

Table 2: Permutation test of the effect of window class (Class), hedgerow segment type (H.Type), Neighbor type (N.Type), their relative orientations (R.Orient) and all two-way interactions on the relative numbers of neighbors $\left(N_{r}^{\Theta}(S, b)\right)$ for neighborhoods of increasing sizes. Df: degrees of freedom.

\begin{tabular}{|c|c|c|c|c|c|c|c|c|c|c|c|}
\hline $\begin{array}{l}\text { Neighborhood } \\
\text { width (m) }\end{array}$ & & 20 & 40 & 60 & 80 & 100 & 120 & 140 & 160 & 180 & 200 \\
\hline$\overline{\text { Durance }}$ & Df & & & & & & & & & & \\
\hline$\overline{\text { Class }}$ & -4 & ns & ns & ns & ns & ns & ns & ns & ns & ns & ns \\
\hline H.Type & 2 & $* *$ & $* *$ & $* *$ & $* *$ & $* *$ & $*$ & $*$ & ns & ns & ns \\
\hline N.Type & 2 & $* *$ & $* *$ & $* *$ & $* *$ & $* *$ & $* *$ & $* *$ & $* *$ & $* *$ & $* *$ \\
\hline R.Orient. & 2 & $* *$ & $* *$ & $* *$ & $* *$ & $* *$ & $* *$ & $* *$ & $* *$ & $* *$ & $* *$ \\
\hline Class*N.Type & 8 & $*$ & ns & ns & $*$ & $* *$ & $* *$ & $* *$ & $* *$ & $* *$ & $* *$ \\
\hline Class* R.Orient & 8 & $*$ & $* *$ & $* *$ & ns & ns & ns & ns & ns & ns & ns \\
\hline Class*H.Type & 8 & ns & ns & ns & ns & ns & ns & ns & ns & ns & ns \\
\hline H.Type*N.Type & 4 & ns & ns & ns & ns & ns & ns & ns & ns & ns & ns \\
\hline H.Type*R.Orient & 4 & $* *$ & $* *$ & $* *$ & $* *$ & $*$ & $*$ & $*$ & ns & $*$ & $*$ \\
\hline N.Type* R.Orient & 4 & $* *$ & $* *$ & ns & ns & ns & ns & ns & ns & ns & ns \\
\hline \multicolumn{12}{|l|}{ Brittany } \\
\hline$\overline{\text { Class }}$ & 5 & ns & ns & ns & ns & ns & ns & ns & ns & ns & ns \\
\hline H.Type & 2 & ns & ns & ns & ns & ns & ns & ns & ns & ns & ns \\
\hline N.Type & 2 & $* *$ & $* *$ & $* *$ & $* *$ & $* *$ & $* *$ & $* *$ & $* *$ & $* *$ & $* *$ \\
\hline R.Orient. & 2 & $* *$ & $* *$ & $* *$ & $* *$ & $* *$ & $* *$ & $* *$ & $* *$ & $* *$ & $* *$ \\
\hline Class*N.Type & 10 & $* *$ & $* *$ & $* *$ & $* *$ & $* *$ & $* *$ & $* *$ & $* *$ & $* *$ & $* *$ \\
\hline Class* R.Orient & 10 & ns & ns & ns & ns & ns & ns & ns & ns & ns & ns \\
\hline Class*H.Type & 10 & ns & ns & ns & ns & ns & ns & ns & ns & ns & ns \\
\hline H.Type*N.Type & 4 & ns & ns & ns & ns & ns & ns & ns & ns & ns & ns \\
\hline H.Type*R.Orient & 4 & ns & ns & ns & ns & ns & ns & ns & ns & ns & ns \\
\hline N.Type* R.Orient & 4 & ns & ns & ns & ns & ns & ns & ns & ns & ns & ns \\
\hline
\end{tabular}


Figure 4: Relative number $N_{r}^{\Theta}(S, b)$ of each type of element (hedgerows, roads and channels) in increasing neighborhoods (20 to $500 \mathrm{~m}$ ) of hedgerow segments for two typical windows (D_5_6 from low Durance valley and B_9_2 from Brittany). $N_{r}^{\Theta}(S, b)$ is given for the two relative orientations (parallel and perpendicular) and in neighborhoods of either all hedgerow segments (left column), only HNS (center column) or only HWE (right column) hedgerow segments.

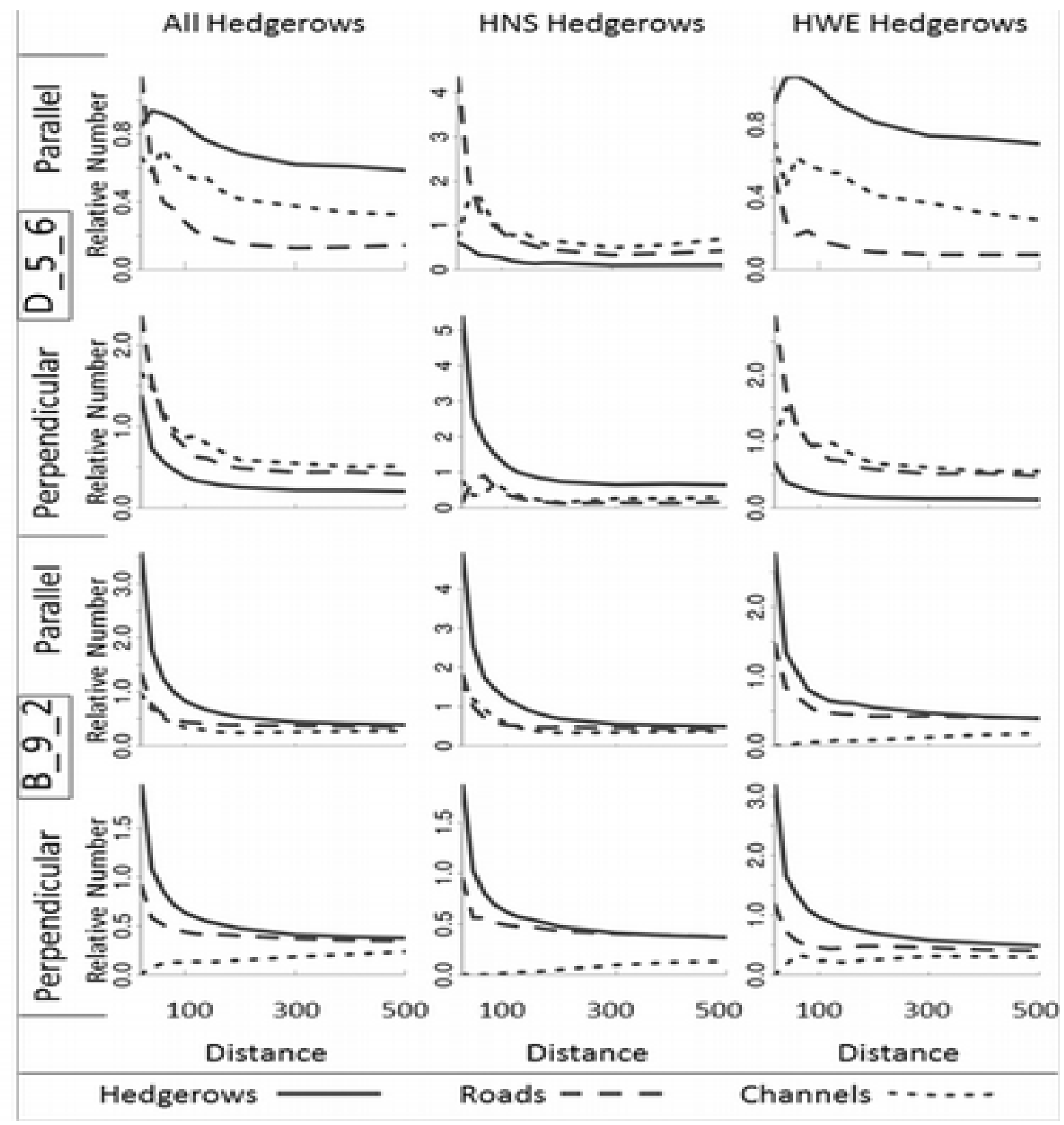


Figure 5: Standardized $N_{r}^{\Theta}(S, b)$ of each type of elements (top: roads, middle: hedgerows, channels: bottom) in increasing neighborhoods of hedgerow segments in each landscape (left: Brittany, right: Durance).__: HNS hedgerows, HWE hedgerows. neighbor with parallel relative orientation, and absence of dot: neighbor with perpendicular relative orientation.
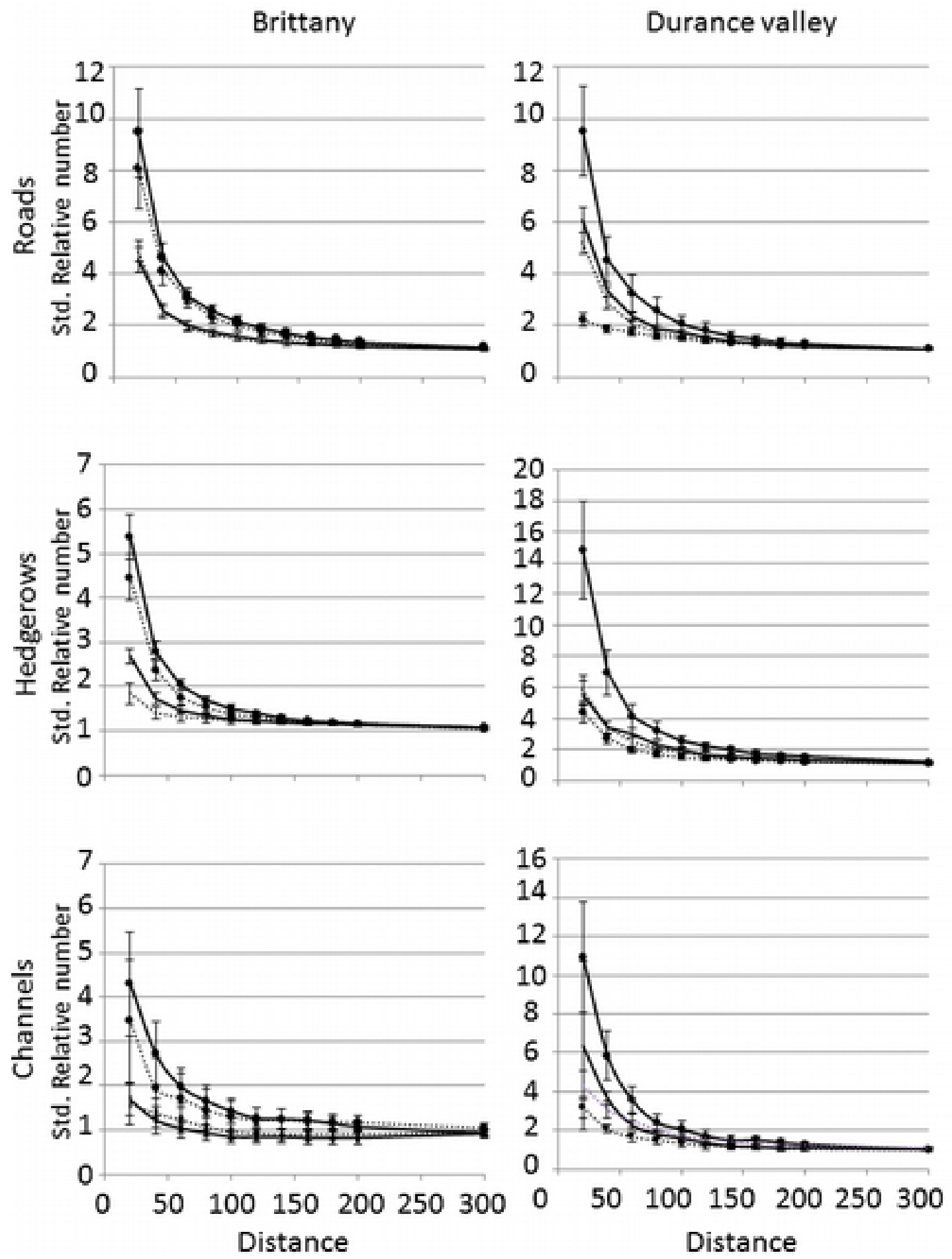


\section{Synthesis considering all windows}

The same general pattern exemplified by windows D5_6 and B9_2 was found when all windows were considered together: hedgerow segments and their neighbors were strongly associated up to a distance of approximately $150 \mathrm{~m}$, except for hedgerow segments parallel to HWE hedgerows in the Durance valley, which showed a more regular pattern (Figure 5).

In both landscapes, the relative number of neighbors of a given hedgerow segment within each distance depended both on the type of neighbor and on its orientation relative to this hedgerow (significant neighbor type $\mathrm{x}$ relative orientation in Table 2). The effect of the neighbor type in Brittany resulted from the weak association of hedgerows and channels (e.g., average over hedgerows of the relative number of channels: 2.92 at $20 \mathrm{~m}$ ), whereas the association between hedgerows and either other hedgerows or roads was stronger (on average, 6.03 and 3.19, respectively, Figure 5). In the low Durance valley, this significant interaction resulted from a lower association of hedgerows among themselves than with channels and roads (on average, 4.77, 6.01 and 6.36, respectively, at $20 \mathrm{~m}$ ). The effect of the relative orientation of the neighbor was particularly clear in Brittany, where the relative number of parallel neighbors was higher than that of perpendicular neighbors for any type of neighbor (Figure 5). In the Durance valley, the "relative orientation" effect was significant as an interaction term with both the hedgerow type and the neighbor type, as detailed below. A major difference between the two landscapes was indeed that hedgerow type (i.e., orientation W/E or N/S, which corresponded to windbreaks or non-windbreaks, respectively, in Durance) was significant both as a main effect and in interaction in the Durance valley but not in Brittany (Table 2). In the Durance valley, the neighbors that showed the strongest shortdistance association and their relative orientation depended on the hedgerow type. HNS hedgerows paralleled roads or channels at a short distance and also had perpendicular hedgerows in their vicinity. In contrast, HWE roads had an intermediate level of shortdistance association with perpendicular roads and hedgerows and exhibited a regular distribution with respect to parallel hedgerows. This effect of the hedgerow group disappeared at a distance of approximately $100 \mathrm{~m}$. Such a pattern was not observed in Brittany. 
Figure 6: Standardized $\mathrm{Nr} \Theta(\mathrm{S}, \mathrm{b})$ of neighboring road and hedgerow elements for two neighborhood sizes (20 $\mathrm{m}$ and $100 \mathrm{~m}$ distance). The results are presented for all hedgerow segments of the Brittany landscape (top) and either HWE (middle) or HNS (bottom) hedgerow segments of the low Durance valley landscape. Grey lines correspond to trends of change for neighbors with parallel relative orientation and black lines for neighbors with perpendicular relative orientation. Each line corresponds to one class with its corresponding number noted on the left.

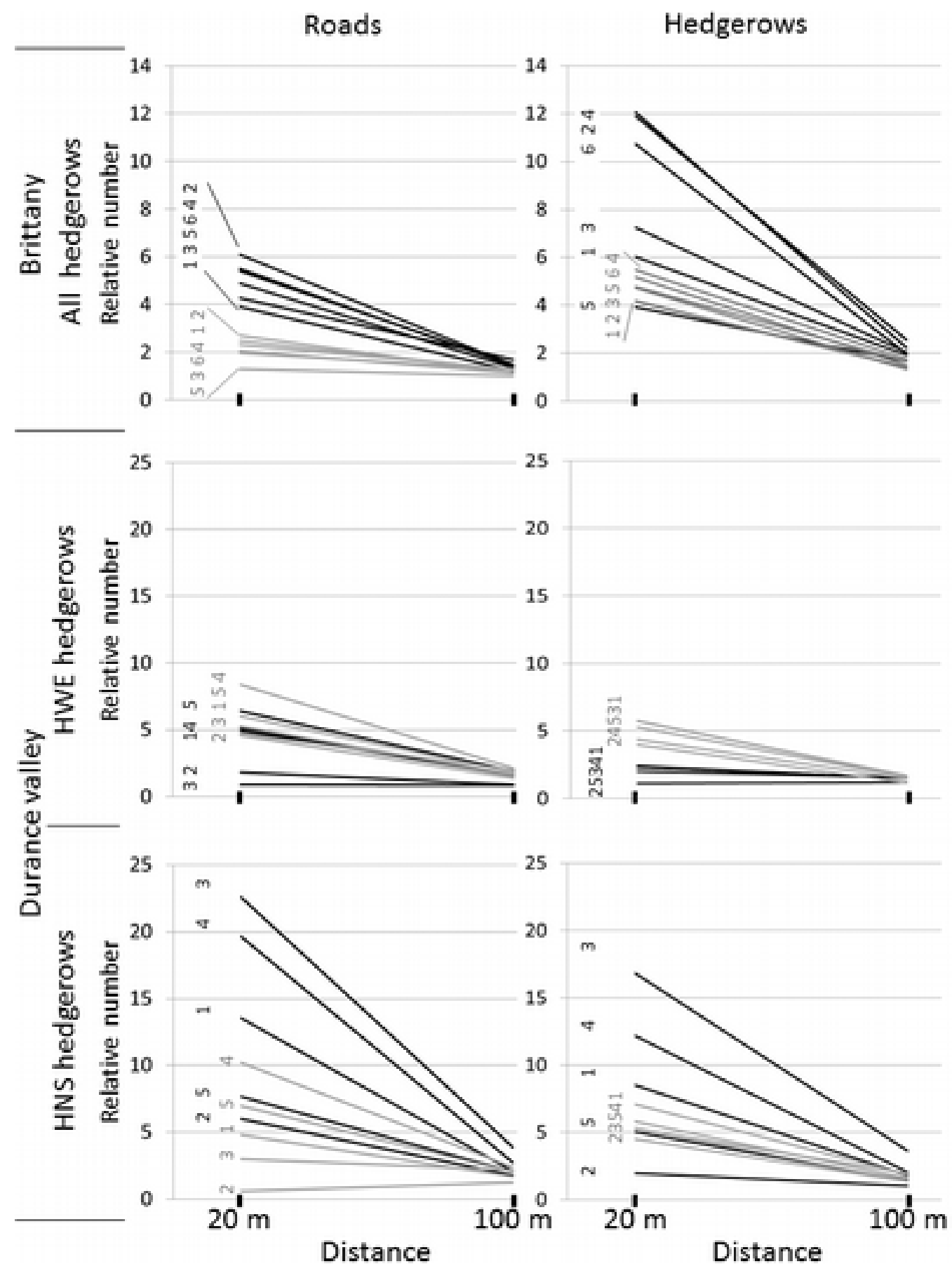


Furthermore, the above results included a certain degree of heterogeneity within landscapes (Figure 6). The effect of the neighbor type, in particular, depended on the window class (class $\mathrm{x}$ neighbor type interaction). In Brittany, for example, hedgerows were very strongly associated with other hedgerow segments but less so with roads at a short distance in certain classes (e.g., in classes 2, 4 and 6 for parallel neighbors) but not in others.

In the low Durance valley landscape, short-distance associations were, furthermore, very strong, with perpendicular but not parallel neighbors in certain classes (e.g., classes 3 and 4 for HNS hedgerows), whereas there was no effect of relative orientation of neighbors in the other classes (Figure 6), resulting in a significant Class*R.Orientation interaction at short distance (until approximately $80 \mathrm{~m}$, Table 2). Classes 3 and 4, which had strongly different association levels depending on the relative orientation of neighbors, comprised the smallest number of hedgerows and roads (Table 1).

\section{Discussion}

In the present study, we characterized the spatial association among hedgerows and between hedgerows and two other linear landscape elements, roads and channels. We showed that hedgerows were generally associated at a short distance with other elements, with a distance effect on hedgerows generally limited to $100-150 \mathrm{~m}$. We examined the role of hedgerow orientation, separating HWE and HNS hedgerows, and proved that these two types of hedgerows had different association patterns in the low Durance Valley but not in Brittany. We lastly found that within-landscape heterogeneity, based on the number of roads and hedgerows, was again related to different association patterns in the low Durance Valley but, apparently, not in Brittany.

The methodology that we used is related to proximity analyses, which are frequently used in landscape ecology to assess the influence of nearby landscape features on the abundance of species in focal patches. This choice was guided both by the type of data that were available and by the questions that we asked. First, our work was based on data that were directly digitized in a GIS. Thus, our approach is clearly distinguished from the majority of existing work dealing with the extraction of networks (hedgerows, roads or channels) from aerial or 
satellite photographs (Stoica, 2001; Monestiez et al., 2005; Lacoste et al., 2005; Vannier, 2010). Second, as we were interested in the spatial organization of hedgerows, we characterized hedgerows by their length and local orientation rather than by other characteristics that are sometimes considered in ecological studies, such as their species richness, width or height (Landis, 2000). For this purpose, we split hedgerows into linear segments and restricted our analysis to the lengths and orientations of these segments. Our data set thus consisted of a set of disconnected linear segments. Consequently, our approach also differs from those based on network analyses. These approaches have primarily been developed for aspatial networks, such as trophic networks (Kay et al., 1989; Fath et al., 2007) in ecology. The more specific analysis of spatial networks, furthermore, does not allow the incorporation of the relative orientation of network segments but only includes the global network orientation (Monestiez et al., 2005; Bailly et al., 2006). We lastly did not use methods based on distances among segment centroids or among ensembles (Cressie, 1993; Lantuéjoul, 2002; Gaetan \& Guyon, 2008) because we were interested in characterizing the proximity from the point of view of an element (e.g., organism, pesticide particle) that would move from one segment to the other or be physically blocked by the short distance between segments. For this reason, we needed to consider a pseudo-distance.

Transforming our data to segments caused a multiplication of the number of hedgerow, road and channel elements relative to the number of the original polylines. For hedgerows, the multiplication factor was rather small in the Durance landscape (approximately 1) but larger (approximately 2) in Brittany. This difference can be explained by the intrinsic characteristics of hedgerows in the two regions (long and straight planted windbreak hedgerows in Durance vs. more spontaneous and diverse hedgerows in Brittany) but also by the data production mode (manual digitization of aerial photographs for the Durance landscape vs. field monitoring of administrative maps for the Brittany landscape). The number of roads and channels increased from fourfold to 28 -fold as a result of the segment transformation, with channels in Brittany having the highest value. Because these last-named data were provided by the same producer (IGN, France) for the two landscapes, the differences can only be explained by the characteristics of the roads and channels themselves: straight roads and long irrigation channels in the Durance valley vs. numerous twisting roads and ditches in Brittany. 
These differences may result from different types of relief: the Durance valley is very flat, as it is part of the Rhône River delta, whereas the Brittany region of interest is relatively undulating.

This multiplier effect increased certain values more in one landscape than in the other, e.g., the number of road segments in the direct neighborhood of a chosen hedgerow may have been artificially increased in Brittany compared with the Durance valley. However, we were not assessing the number of elements but, rather, the over/under-representation of different neighbor types in the vicinity of hedgerows. For this reason, we computed the relative numbers of neighbors to minimize this artifact: the number of segments (of roads, channels or hedgerows) in a neighborhood was related to the density of the same segment types in the current target area. This approach allowed the analysis of the composition of hedgerow neighborhoods within a window with regard, e.g., to the relative orientation of neighbors. Differences between the two landscapes and a certain degree of within-landscape heterogeneity could then be highlighted.

Our aim was also to check distances over which associations between elements could be observed. For this purpose, the neighbor numbers were computed within an increasing buffer surrounding the target hedgerow, resulting in averaging effects, with large neighborhoods including both near and far neighbors. Most likely, this method overestimates distances at which elements are associated. Another solution could have been to compute neighbor numbers in successive rings, as proposed in some proximity analyses (e.g., Carriere et al., 2012). However, this approach would have been both impractical (because the presence of a segment within a ring could not have been determined simply from the smallest distance between segments) and not consistent with our assumption that the influence of a segment propagates gradually to its neighbors.

The method used in this study served to unravel the characteristics of hedgerow structures in the two regions. It effectively detected the generally short distance of association between hedgerows and other elements. This distance of effect on hedgerows was generally limited to $100-150 \mathrm{~m}$ in both landscapes but generally decreased in the first few meters, indicating that hedgerows were generally grown next to other landscape elements. The principal exception 
was the regular pattern of hedgerows in the Durance valley. This pattern is apparent in the landscape and can be explained by the overall similar areas $(0.85$ ha on average, Ricci et al., 2009) and shapes of orchards that lay between windbreak hedgerows.

Hedgerows with different orientations had different relationships to other linear elements in the Durance valley but not in Brittany. This result is consistent with the windbreak role of HWE hedgerows in the Durance valley. HWE hedgerows are planted between or even within orchards to prevent wind damage to the fruit. For this reason, a regular and dense distribution of HWE hedgerows is targeted by the fruit growers to avoid areas with high winds. In contrast, hedgerows are primarily spontaneous or grown as fences and for wood production in Brittany, and the function of hedgerows does not relate to their orientation (Liagre, 2006).

We also investigated within-landscape heterogeneity. The window classification was efficient for separating areas with various densities, as it was computed according to the number of elements in the windows. Furthermore, it was able to distinguish windows with respect to hedgerow orientation and neighbor types. The reason for this outcome is that in Durance, lowdensity areas (classes 3, 4 in the southwestern part of the landscape) are cropping zones, with few windbreak HWE hedgerows but, rather, roadside HNS hedgerows. In contrast, highdensity areas are orchard areas with numerous windbreak hedgerows. In Brittany, low-density areas (classes 3, 4 and 5, the northern part of the landscape) correspond to consolidated lands, whereas high-density areas are dense "bocage" zones.

\section{Conclusions}

Using proximity analyses, we assessed whether and under what circumstances the spatial distribution of hedgerows was impacted by the position of perennial linear landscape elements and the scale of the effects of these elements for two contrasting agricultural landscapes. We proposed, therefore, to compute a neighborhood index at different distances and showed that it was effective in revealing structures at various scales according to the types of elements involved. The observed associations between element types suggest that experimental studies of the role of hedgerows in ecological processes should also recognize the effects of shortdistance neighbors of hedgerows, such as roads or channels, to avoid confounding effects. 
In terms of our modeling aim, the dependence assumption between hedgerows and perennial lines (roads, channels) was confirmed. Furthermore, we showed that the distance over which this dependence occurred was limited to 100-150 m, suggesting that the modeling should be performed at this scale. Lastly, by examining the role of hedgerow direction, separating HWE and HNS hedgerows, we also proved that modeling these two types of hedgerows separately was pertinent in the low Durance Valley but apparently not in Brittany.

According to these results, we propose to model and simulate hedgerows based on neighboring perennial lines (roads and channels) and other hedgerows using fiber processes (Stoyan et al., 1987) up to a specified distance. Simulating hedgerows is useful for studying the sensitivity of ecological models to landscape characteristics, an approach similar to that used for gene flow models (Le Ber et al., 2009). This approach is also useful for optimizing the location of hedgerows to address ecological quality and landscape character (Groot et al., 2010) or for risk reduction, as discussed by Meyer et al. (2012). In terms of this last-named approach, which is based on a simple grid of segments, we could define more realistic structures of hedgerows based on perennial lines in the targeted landscapes.

\section{Acknowledgments}

The authors warmly thank LETG-Rennes-COSTEL and the Zone Atelier Armorique, France, who provided the Brittany data, and B. Ricci and J.-C. Bouvier (INRA PSH), who digitized the low Durance Valley hedgerows. The first author benefited from an INRA-INRIA CJS PhD grant. This work was partially funded by the Payote network.

\section{References}

Bailly, J. S., Monestiez, P., \& Lagacherie, P. (2006). Modelling spatial variability along drainage networks with geostatistics. Mathematical geology, 38(5), 515-539.

Bennett, A. F., Radford, J. Q., \& Haslem, A. (2006). Properties of land mosaics: implications for nature conservation in agricultural environments. Biological Conservation, 133(2), $250-264$. 
Burel, F. (1996). Hedgerows and their role in agricultural landscapes. Critical reviews in plant sciences, 15(2), 169-190.

Carriere, Y., Goodell, P.B., Ellers-Kirk, C., Larocque, G., Dutilleul, P., Naranjo, S.E., Ellsworth, P.C. (2012), Effects of Local and Landscape Factors on Population Dynamics of a Cotton Pest, PLOS ONE, 7(6), e39862.

Chaplin-Kramer, R., O’Rourke, M. E., Blitzer, E. J., \& Kremen, C. (2011). A meta-analysis of crop pest and natural enemy response to landscape complexity. Ecology letters, 14(9), 922932.

Cressie, N. A. (1993). Statistics for Spatial Data, revised edition (Vol. 928). New York, NY: J. Wiley.

Davies, Z. G., \& Pullin, A. S. (2007). Are hedgerows effective corridors between fragments of woodland habitat? An evidence-based approach. Landscape ecology, 22(3), 333-351.

De Smith, M.J., Goodchild, M.F., \& Longley, P. A. (2007). Geospatial Analysis: A Comprehensive. Guide to Principles, Techniques and Software Tools. Leicester: Troubador.

Fath, B. D., Scharler, U. M., Ulanowicz, R. E., \& Hannon, B. (2007). Ecological network analysis: network construction. Ecological Modelling, 208(1), 49-55.

Gaucherel, C., Fleury, D., Auclair, D., \& Dreyfus, P. (2006). Neutral models for patchy landscapes. Ecological modelling, 197(1), 159-170.

Geiger, F., Wäckers, F. L., \& Bianchi, F. J. (2009). Hibernation of predatory arthropods in semi-natural habitats. Biocontrol, 54(4), 529-535.

Gaetan, C., \& Guyon, X. (2008). Modélisation et statistique spatiales (Vol. 63). Berlin: Springer-Verlag.

Groot, J.C.J., Jellema, A., \& Rossing, W.A.H. (2010). Designing a hedgerow network in a multifunctional agricultural landscape: Balancing trade-offs among ecological quality, landscape character and implementation costs. European Journal of Agronomy, 32(1), $112-$ 119.

Guyot, G., (1997). Climatologie de l'environnement : De la plante aux écosystèmes, Paris: Masson.

Kay, J. J., Graham, L. A., \& Ulanowicz, R. E. (1989). A detailed guide to network analysis. In F. Wulff, J.G. Field, \& K.H. Mann (Eds), Network Analysis in Marine Ecology: Methods and Applications. Berlin: Springer-Verlag.

Lacoste, C., Descombes, X., \& Zerubia, J. (2005). Point processes for unsupervised line network extraction in remote sensing. Pattern Analysis and Machine Intelligence, IEEE Transactions on, 27(10), 1568-1579. 
Landis, D. A., Wratten, S. D., \& Gurr, G. M. (2000). Habitat management to conserve natural enemies of arthropod pests in agriculture. Annual Review of Entomology, 45(1), 175-201.

Lantuejoul, C. (2001). Geostatistical simulation: models and algorithms. Berlin: SpringerVerlag.

Larcher, F. \& Baudry, J. (2013). Landscape grammar: a method to analyse and design hedgerows and networks. Agroforestry Systems 87, 181-192.

Le Ber, F., Lavigne, C., Adamczyk, K., Angevin, F., Colbach, N., Mari, J. F., \& Monod, H. (2009). Neutral modelling of agricultural landscapes by tessellation methods-Application for gene flow simulation. Ecological Modelling, 220(24), 3536-3545.

Liagre, F. (2006). Les haies rurales : rôles, création, entretien. Paris : La France Agricole.

Lotfi, A., Javelle, A., Baudry, J., \& Burel, F. (2010). Interdisciplinary Analysis of Hedgerow Network Landscapes' Sustainability. Landscape Research 35(4),415-426.

Mazzi, D., \& Dorn, S. (2012). Movement of insect pests in agricultural landscapes. Annals of Applied Biology, 160(2), 97-113.

Martin, A. E., \& Fahrig, L. (2012). Measuring and selecting scales of effect for landscape predictors in species-habitat models. Ecological Applications, 22(8), 2277-2292.

Meyer, B. C., Wolf, T. and Grabaum, R. (2012). A multifunctional assessment method for compromise optimisation of linear landscape elements. Ecological Indicators, 22, 53-63.

Meynier, A. (1958), Les paysages agraires. Paris: A. Colin.

Monestiez, P., Bailly, J. S., Lagacherie, P., \& Voltz, M. (2005). Geostatistical modelling of spatial processes on directed trees: Application to fluvisol extent. Geoderma, 128(3), 179191.

Ouin, A., Martin, M., \& Burel, F. (2008). Agricultural landscape connectivity for the meadow brown butterfly (Maniola jurtina). Agriculture, Ecosystems \& Environment, 124(3), 193 199.

Paletto, A. \& Chincarini, M. (2012). Heterogeneity of linear forest formations: differing potential for biodiversity conservation. A case study in Italy. Agroforestery Systems 86, 8393.

Ricci, B., Franck, P., Toubon, J. F., Bouvier, J. C., Sauphanor, B., \& Lavigne, C. (2009). The influence of landscape on insect pest dynamics: a case study in southeastern France. Landscape ecology, 24(3), 337-349. 
Riitters, K. H., O'neill, R. V., Hunsaker, C. T., Wickham, J. D., Yankee, D. H., Timmins, S. P., Jones, K.B., \& Jackson, B. L. (1995). A factor analysis of landscape pattern and structure metrics. Landscape ecology, 10(1), 23-39.

Ripley, B.D. (1981). Spatial statistics., New York, N.Y.: J. Wiley

Stoica, R. (2001). Processus ponctuels pour l'extraction de réseaux linéiques dans les images satellitaires et aériennes (Doctoral dissertation, Nice Sophia-Antipolis University).

Stoyan, D., Kendall, W.S., Mecke, J., \& Ruschendorf, L. (1987). Stochastic geometry and its applications (Vol. 2). New York, NY.: J. Wiley.

Turner, M. G., \& Gardner, R. H. (1991). Quantitative methods in landscape ecology. New York, N.Y.: Springer-Verlag.

Tyson, R., Thistlewood, H., \& Judd, G.J. (2007). Modelling dispersal of sterile male codling moths, Cydia pomonella, across orchard boundaries. Ecological modelling, 205(1), 1-12.

van der Zanden, E.H., Verburg, P.H., \& Mucher, C.A. (2013). Modelling the spatial distribution of linear landscape elements in Europe. Ecological Indicators 27, 125-136.

Vannier, C., \& Hubert-Moy, L. (2010, July). Wooded hedgerows characterization in rural landscape using very high spatial resolution satellite images. In Geoscience and Remote Sensing Symposium (IGARSS), 2010 IEEE International (pp. 347-350). New York, N.Y. : IEEE.

Wiegand, T., Moloney, K. A., Naves, J., \& Knauer, F. (1999). Finding the missing link between landscape structure and population dynamics: a spatially explicit perspective. The American Naturalist, 154(6), 605-627. 